\title{
Antimalarial Activity of Ethanol Extract of Noni Leaves (Morinda citrifolia) towards Parasitemia, Splenomegaly, and Hepatomegaly in Plasmodium berghei ANKA Infected Mice
}

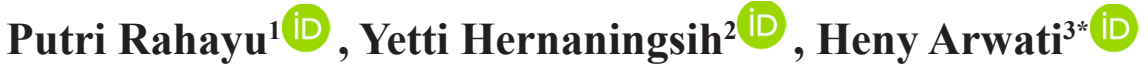 \\ ${ }^{1}$ Faculty of Medicine, Universitas Airlangga, Surabaya, Indonesia \\ ${ }^{2}$ Department of Clinical Pathology, Faculty of Medicine, Universitas Airlangga, Surabaya, Indonesia \\ ${ }^{3}$ Department of Parasitology, Faculty of Medicine, Universitas Airlangga, Surabaya, Indonesia
}

\section{A R T I C L E I N F O}

\section{Article history:}

Received 28 May 2021

Received in revised form 15 June 2021

Accepted 17 June 2021

Available online 30 June 2021

\section{Keywords:}

Morinda citrifolia,

Antimalaria activity,

Hepatomegaly,

Splenomegaly.

*) Corresponding author:

arwatiheny@yahoo.com

\begin{abstract}
A B S T R A C T
Introduction: Malaria is one of the infectious diseases found in tropical countries and sub-tropical countries. In 2016 there were an estimated 445,000 people died to malaria. Alternative medicine is needed, such as natural based ingredient. Morinda citrifolia or noni plant is a medicinal plant found in all parts of Indonesia which has many benefits, such as antibacterial, analgesic, anticancer, antioxidant, and anti-inflammatory. The aims of this study were to determine the antimalarial activity of ethanol extract of noni leaves and its effect on splenomegaly and hepatomegaly.

Methods: Extract of noni leaves was prepared by maceration using ethanol solvent. In vivo experiments were conducted using Plasmodium berghei infected BALB/c mice treated with the doses of $100,10,1 \mathrm{mg} / \mathrm{kg}$ body weight(BW) orally of ethanolic extract of noni leaves. Then, the percentage of parasitemia was calculated from day 1 to day 4 after treatment and at the end of the test, mice were sacrificed then spleen and liver were collected.

Results: The highest parasite growth was found in the group treated with noni leaves ethanol extract at a dose of $1 \mathrm{mg} / \mathrm{kg} \mathrm{WB}$ and vice versa. Probit analysis resulted in ED50 was $0.882 \mathrm{mg} / \mathrm{kg}$ WB. Spearmen test showed there was no correlation between doses and the size of splenomegaly with $\mathrm{p}=0,2$ and between doses and the size of hepatomegaly with $\mathrm{p}=0,6$.

Conclusion: Ethanol extract of noni leaves possessed antimalaria activity and there was no correlation between doses of extract and the splenomegaly and hepatomegaly.
\end{abstract}

\section{Introduction}

Malaria is an infectious disease which has spread to almost all over the world with tropical and sub-tropical climate. ${ }^{1}$ This disease is caused by parasites from the genus Plasmodium and transmitted by the bite of female Anopheles mosquitoes. Physical examination results found in patients are generally fever, pale on the conjunctiva or palms, spleen enlargement (splenomegaly), and liver enlargement (hepatomegaly). ${ }^{2}$ Malaria is an endemic disease in various poor countries and tropical developing countries such as Africa, Asia, and Latin America. The World Malaria Report even states that malaria is in 106 countries in the world. In 2015, in the world there were 429,000 deaths from malaria. The following year in 2016 there were 216 million cases of malaria and 445,000 people died. However, the heaviest cases occur in Africa because $90 \%$ of deaths in the region are caused by malaria, and more than two-thirds of deaths occur in children under 5 years of age. ${ }^{3}$ In Indonesia, the regions located in the eastern part have high Annual Parasite Insidence (API) compared to other regions, API is the number of malaria positive cases per 1000 inhabitants in one year. ${ }^{4}$

Parasite resistance to antimalaria drugs such as quinine, chloroquin, and pyrimethamine-sulfadoksin has occurred in 3 of the 5 types of malaria that attack humans, namely Plasmodium falciparum, Plasmodium vivax, and Plasmodium malaria. This can be caused partly by irrational use of antimalarial drugs and patient non-compliance with the drug until it runs out. The latest malaria treatment uses a combination drug derived from Artemisinin known as Artemisinin based Combination Therapy (ACT). This combination is given to increase effectiveness and prevent resistance.

To overcome this resistance problem, one of which is the need for other alternative medicines that can play a role in curing malaria. The use of natural ingredients as anti-malarial 
drugs is one of the right choices, considering that there are many herbal plants that have medicinal properties in Indonesia. Medicinal plant on of them is noni (Morinda citrifolia) or pace in Indonesian language is a plant that is often found in all regions of Indonesia and now extends to other tropical countries. Noni plants have many benefits for human health, such as antibacterial, analgesic, anticancer, antioxidant, antiinflammatory, and can enhance immunity. ${ }^{5}$ Noni leaves can act as antibacterial because they contain chemical compounds such as anthraquinone, alkaloids, saponins, flavonoids, and terpenoid. ${ }^{6}$ Ethanol extract of noni leaves was stated to have antimalarial activity against $P$. falciparum $3 \mathrm{D} 7$ strain with an IC value of $22.68 \mu \mathrm{g} / \mathrm{mL}$.

Compounds content of extracts that can be extracted by solvents during the extraction process, play a role in various pharmacological activities. Therefore, the selection of solvents is important in the extraction process. In this study, the solvent used was ethanol. Ethanol is a non-toxic solvent that can dissolve the chemical components found in plants, both polar and non-polar. ${ }^{8}$

This current study will used ethanol extract of noni leaves againts on parasitemia, splenomegaly, and hepatomegaly in $\mathrm{BALB} / \mathrm{c}$ mice infected with Plasmodium berghei ANKA. The $\mathrm{BALB} / \mathrm{c}$ mice are used as an experimental animal because the simiarities in the reaction towards the disease, treatment, and physiological condition with human. ${ }^{9}$

The $P$. berghei ANKA parasites has been widely used for research on the development of anti-malarial drugs with various plant extracts. ${ }^{10,11}$

This research was conducted considering the number of cases of resistance of plasmodium parasites to anti-malarial drugs such as chloroquine pyrimethamine-sulfadoxine and quinine. ${ }^{11}$

\section{Methods}

\section{Study design}

This research was laboratory experimental which aims to determine the effect of ethanol extract of noni leaves on parasitemia, splenomegaly, and hepatomegaly. The study was conducted from February to June, 2018.

\section{Ekstract}

The ethanol extract of noni (Morinda citrifolia) leaves used in this study was obtained from Batu who was identified at the Center for Materia Medica, East Java. The ethanol extract of noni leaves is made by soaking $1 \mathrm{~kg}$ of dry leaf simplicia with $96 \%$ ethanol solvent at least twice the volume of powder, shaken, stored for 24 hours then filtered. Repeat the process 2 times. Then the extraction is evaporated in a water bath at $40^{\circ} \mathrm{C}$ until the stability of the extract is achieved.

\section{Experimental method}

The parasite used in this study were the Plasmodium berghei ANKA strains obtained from the Department of Parasitology, Universitas Airlangga, Surabaya. The parasite was present in the frozen blood of mice. The frozen blood infected with P. berghei ANKA was thawed at $37^{\circ} \mathrm{C}$ and then inoculated in 5 donor mice as much as $200 \mu \mathrm{L}$ intraperitoneally. After parasitemia reaches $15-20 \%$ in donor mice, the mice are operated on and blood is drawn from the heart using a syringe. Blood is put into a test tube containing EDTA anticoagulant and mixed for parasite homogenization. Blood was then inoculated $0.2 \mathrm{ml}$ each of the test mice intraperitoneally.
The experimental animals used in this study were 8 weeks old male BALB/c strain mice weighting 20-25 grams obtained from the experimental Animal Unit of the Department of Biochemistry, Faculty of Medicine, Universitas Airlangga. Mice were acclimatized for 7 days, given special pellet feed for mice and given mineral water every day at $1 \mathrm{pm}$.

The 25 of mice were injected with $0.2 \mathrm{ml}$ each of the test mice intraperitoneally of $P$. berghei ANKA infected erithrocyte and divided into 5 groups with each group consisted of 5 mice. Based on drug and extract treatment, Group 1, was a positive control group which treated with $20 \mathrm{mg} / \mathrm{kg} \mathrm{BW}$ orally chloroquin diphosphate; Group 2, was a negative control group, without any additional treatment; Group 3,4,5, test groups which were given the ethanol extract of noni leaves at a doses of 100, 10, and $1 \mathrm{mg} / \mathrm{kg} \mathrm{BW}$ orally. The test was carried out by giving ethanol extract of noni leaves for 4 consecutive days starting from the 5 th day after infection of the test mice. This antimalarial activity test was carried out in vivo using a modified Peter method, where the treatments were done for 4 consecutive days (D1-D4). 12 Blood of mice were taken everyday from the tip of the tail to prepare blood smear, then stained with $10 \%$ Giemsa prior to parasitemia observation. The parasitemia was calculated by counting the number of infected erythrocytes in 1000 erythrocytes. Based on the persentages of parasitemia, then the percentages of parasitemia growth and percent inhibition were calculated using the following formula: ${ }^{13}$

$$
\% \text { growth }=\frac{\sum(\mathrm{Dx}-\mathrm{Dx}-1)}{\mathrm{n}-1}
$$

Where: $(\mathrm{Dx}-\mathrm{Dx}-1)=\%$ parasitemia on $\mathrm{x}$-day minus $\%$ parasitemia on day before, $n=$ number of observation day.

$$
\% \text { inhibition }=\left(\left|\frac{\mathrm{Xe}}{\mathrm{Xk}}\right| \times 100 \%\right)
$$

Where: $\mathrm{Xe}=$ percent growth of the average parasite in the group given the test solution, $\mathrm{Xk}=$ percent of average parasite growth in negative control.

Probit analysis using the SPSS 20 program was used to determine ED50 or Effective Dose 50 which was able to inhibit $50 \%$ of $P$. berghei ANKA growth in mice. Spearman test to analyze the relationship between the ethanol extract dose of Noni leaves with splenomegaly and hepatomegaly. The data were correlated significantly if $\mathrm{p}<0.05$.

\section{Ethical Clearance}

This study was approved by Health Research Ethics Commitee, Faculty of Medicine, Universitas Airlangga, Surabaya with ethical number 341/EC/KEPK/FKUA/2017.

\section{Results}

\section{Percentages of Parasitemia}

Percentage of parasitemia in BALB/c mice infected with $P$. berghei ANKA given a 4-day test solution are listed in Table 1. 
Percentages of Growth and Inhibition of Parasitemia Growth

Percentages of growth and inhibition of parasitemia in group treated with ethanol extract of noni leaves, positive control and negative control are shown in Table 2.

The highest growth was found in the group treated with ethanol extract of noni leaves at $1 \mathrm{mg} / \mathrm{kg} \mathrm{BW}$, whereas, the lowest growth was in the group treated with dose of $100 \mathrm{mg} /$ $\mathrm{kg} \mathrm{BW}$. The higher inhibition was found in the group treated with ethanol extract of noni leaves with dose of $100 \mathrm{mg} / \mathrm{kg}$ $\mathrm{BW}$, whereas, the lowest inhibition was found in the group treated with dose $1 \mathrm{mg} / \mathrm{kg} \mathrm{BW}$. The effect of ethanol extract of noni leaves showed that the higher doses of extract gave the lower persentages of parasitemia growth, inversely gave the higher persentages of inhibition of parasitemia growth.

Comparison of persentages of parasitemia growth in mice treated with ethanol extract of noni leaves and negative control showed that, the persentages of parasitemia growth in extract-treated mice were lower than that in negative control indicated that ethanol extract of noni leaves influenced the parasitemia growth during the 4 day course of treatment.

Persentages of inhibition of parasitemia growth were lower than positive control, indicated that the extract was able to inhibit parasit growth, although less potent than Chloroquin, since the $P$. berghei ANKA is chloroquin sensitive parasites.

\section{Effective Dose (ED50)}

Probit analysis resulted in ED50 of $0.882 \mathrm{mg} / \mathrm{kg} \mathrm{BW}$. The ethanol extract of noni leaves was able to kill $50 \%$ infected erithrocyte at the dose of $0.882 \mathrm{mg} / \mathrm{kg} \mathrm{BW}$. The antiplasmodium value in vivo has very good activity if ED50 < $10 \mathrm{mg} / \mathrm{kg}$; good if ED50 10-100 mg/kg; moderate if ED50 is $100-1000 \mathrm{mg} / \mathrm{kg}$; and the antimalarial activity is not defined if ED50>1000 mg/kg. ${ }^{17}$

\section{Analysis of Splenomegaly and Hepatomegaly}

Enlargement size was compared with the size of those organs in normal size where the size of spleen was $0.72 \mathrm{~cm} 2-1.25$ $\mathrm{cm} 2$ and liver was $4.4 \mathrm{~cm} 2-5.06 \mathrm{~cm} 2$. The averages size of spleen and liver after treated with ethanol extract of noni leaves compared with positive control were summarised in Table 3.

The normality test of the data using Shapiro-Wilk test showed that the data was abnormally distributed. The analysis data was followed by Spearman correlation test. Spearmen test resulted from correlation between spleen and doses were $\mathrm{p}=0.2$ indicated there was no significant correlation, as well as the correlation between liver and doses were $\mathrm{p}=0.6$ indicated there was no significant correlation too.

Table 1. Average of parasitemia (\%) in BALB/c mice infected with P. berghei ANKA with treatment

\begin{tabular}{ccccccc}
\hline Treatment & $\begin{array}{c}\text { Doses(mg/ } \\
\text { kgBW })\end{array}$ & Day 0(\%) & Day 1(\%) & Day 2(\%) & Day 3(\%) & Day 4(\%) \\
\hline Group 1 & 1 & 13.8 & 19.29 & 22.75 & 29.59 & 22.04 \\
\hline Group 2 & 10 & 14.44 & 18.8 & 21.98 & 26.19 & 20.22 \\
\hline Group 3 & 100 & 15.1 & 17.95 & 18.94 & 19.83 & 16.22 \\
\hline PC & 20 & 14.09 & 5.57 & 3.16 & 3.65 & 0.78 \\
\hline NC & - & 11.34 & 15.91 & 20.43 & 26.61 & 29.69 \\
\hline
\end{tabular}

Table 2. Averages percent of growth and percent inhibition of P. berghei ANKA after administration ethanol extract of noni's leaves

\begin{tabular}{cccc}
\hline Treatment & Doses $(\mathrm{mg} / \mathrm{kgBW})$ & \% growth & \% inhibit \\
\hline Group 1 & 1 & 2.06 & 55.08 \\
\hline Group 2 & 10 & 1.44 & 68.50 \\
\hline Group 3 & 100 & 0.28 & 93.92 \\
\hline PC & 20 & - & 100 \\
\hline NC & - & 4.59 & - \\
\hline
\end{tabular}

Table 3. Average of liver and spleen size of treated mice

\begin{tabular}{llccc}
\hline & Treatment & Doses $(\mathrm{mg} / \mathrm{kg} \mathrm{BW})$ & Size $(\mathrm{cm} 2)$ & Spleen \\
\hline & & 1 & 6.90 & 1.94 \\
\hline & Group 1 & 10 & 5.99 & 2.24 \\
\hline & Group 2 & 4.90 & 1.95 \\
\hline Group 3 & 100 & 4.94 & 1.77 \\
\hline PC & PC & 20 & 5.75 & 1.73 \\
NC & $:$ Negitive control & &
\end{tabular}




\section{Discussion}

The results of this study showed an ED50 of ethanol extract on $P$. berghei ANKA was $0.882 \mathrm{mg} / \mathrm{kg}$ BW. Thus, it can be said that the smaller the value of ED50 a dose of the test material, the higher the antimalarial activity of the test material. The relatively small ED50 value indicated that ethanol extract of noni leaves is potential to be developed as an antimalaria drug in the future..$^{15}$

The use of ethanol extract of noni leaves in this study was based on active compounds those are anthraquinone, alkaloids, saponins, flavanoids, and terpenoids. ${ }^{6}$ Noni (M. citrifolia) is a member of Rubiaceae family with 9 other sub-families namely Rubia, Cinchona, Coffea, Ixora, Mussaenda, Gardenia, Uncaria, Uragoga, and Pausingstalia. ${ }^{14}$ Another famous Rubiaceae member is used as an anti-malarial drug, Cinchona. Antimalarial activity originates from alkaloid compounds especially kinin and kinidin isolated from the bark of the Cinchona or the quinine tree. ${ }^{15}$ Based on the chemotaxonomic approach, namely an approach that states the similarity of anatomical, histological, morphological, and contained substances, plants originating from the same taxon has a strong kinship in the content of compounds, especially at the level of family, genus, and species. Based on the same approach, several plant species from different families including Meliaceae, Piperaceae, Acanthaceae, Myrtaceae, Myrsinaceae, Solanaceae and Fabaceae were also stated to have antimalarial activity. ${ }^{16}$

Research on noni leaves was previously carried out in vitro at the Laboratory of Tropical Diseases, Airlangga University. Among them stated that the ethanol extract of noni leaves had anti-malaria activity against $P$. falciparum $3 \mathrm{D} 7$ strain with an IC value of $22.68 \mu \mathrm{g} / \mathrm{mL}$. ${ }^{7}$ In this case, the main components that have an antimalarial effect on noni leaves are flavonoids and alkaloids. Another study using noni leaves juice proved to inhibit the growth of E. coli bacteria because it also contains active flavonoids, alkanoids and atrakuinon. ${ }^{6}$

The ethanol extract of noni leaves in this study was given for 4 days. Based on the percentages growth and inhibition after being given ethanol extract of noni leaves, it was found that the extract dose tested was directly proportional to the percent inhibition and inversely proportional to the percentage of parasite growth. Mice that given higher doses of noni leaves extract showed higher percent inhibition and lower percent growth, and vice versa.

Splenomegaly and hepatomegaly as the clinical signs of malaria infection that caused by numbers of infected erythrocytes phagocytosed by macrophages in the spleen and Kupffer cells in the liver. ${ }^{17,18}$ Malaria infection involve a humoral and cellular immune response in the host to eliminate parasites. Spleen plays a role in cellular immunity to filter infected erythrocytes. The increased number of infected erythrocytes activates immune cells, such as macrophages for phagocytosis. Macrophage cells in the spleen also phagocytose hemozoin (malaria pigment). Spleen and liver in malaria infection are not only enlarged but also become dark brown due to ingestion of hemozoin and hemosiderin. The hemozoin pigment originate from changes in hemoglobin from the ingestion of erythrocytes by parasites, while hemosiderin, the brown substance of ferritin oxide that remains from the breakdown of hemoglobin. ${ }^{19}$

In this study, the spleen and liver from mice were measured on the last day of observation of parasitemia, which was the fourth day. The result of spleen and liver measurements had no correlation with the dose of the extract either splenomegaly or hepatomegaly. This means that splenomegaly and hepatomegaly that occur are not affected by the dose of extract. It was proved that in the mice with the largest test dose treatment that was $100 \mathrm{mg} /$ $\mathrm{kg} \mathrm{BW}$ also experienced splenomegaly and hepatomegaly with an organ size that was almost the same as the smaller test dose treatment.

In this study, chloroquine-treated mice in positive control also showed splenomegaly and hepatomegaly, despite parasitemia was decreased since administration of chloroquine. Chloroquine is classified as a blood schizonticidal drug, therefore, its effect does not reach the parasites in the tissues. Splenomegaly and hepatomegaly in all treated mice, thus the ethanol extract of noni leaves has a similar mechanism of action with chloroquine which affects parasites that are circulating in the blood but not in tissues. ${ }^{20}$

\section{Conclusion}

Ethanol extract of noni leaves has very good antimalarial activity in inhibiting the growth of P. berghei ANKA with similiar mechanism to chloroquin with ED50 values of $0.882 \mathrm{mg} / \mathrm{kg} \mathrm{BW}$. Therefore, ethanol extract of noni leaves has the potential to be further developed as an antimalarial.

\section{Conflict of Interest}

The author stated there is no conflict of interest

\section{References}

1. May L, Mullins P, Pines J. Demographic and Treatment Patterns for Infections in Ambulatory Settings in the United States, 20062010. Wilbur L, editor. Acad Emerg Med. 2014 Jan;21(1):17-24.

2. Centers for Disease Control and Prevention. Ambulatory Medical Care Utilization Estimates for 2017. 2007.

3. Depkes RI. Survey Demografi dan Kesehatan Indonesia. Jakarta; 2014.

4. Mosesa SP, Kalesaran AFC, Kawatu PAT. Faktor-faktor yang Berhubungan dengan Kejadian Infeksi Saluran Kemih pada Pasien Poliklinik Penyakit dalam di RSU GMIM Pancaran Kasih Manado. Vol. 897. 2016.

5. Foxman B. Urinary Tract Infection Syndromes. Occurrence, Recurrence, Bacteriology, Risk Factors, and Disease Burden. Infect Dis Clin North Am [Internet]. 2014;28(1):1-13. A

6. Flores-Mireles AL, Walker JN, Caparon M, Hultgren SJ. Urinary tract infections: Epidemiology, Mechanisms of Infection and Treatment Options. Nat Rev Microbiol. 2015;13(5):269-84.

7. Hsiao C, Yang H, Chang C, Lin H, Wu C, Hsiao M, et al. Risk Factors for Development of Septic Shock in Patients with Urinary Tract Infection. Biomed Res Int. 2015;2015:1-7.

8. Castle N, Engberg JB, Wagner LM, Handler S. Resident and Facility Factors Associated with the Incidence of Urinary Tract Infections Identified in the Nursing Home Minimum Data Set. J Appl Gerontol. 2017;36(2):173-94.

9. Lee EK, Teo A, Land G, Borrell S, Spelman D, Leong T, et al. Risk Factors Associated with Urinary Tract Infections in Intensive Care Patients. Infect Dis Heal. 2016;21(2):62-6.

10. Chiță T, Timar B, Muntean D, Bădiţoiu L, Horhat F, Hogea E, et al. Urinary Tract Infections in Romanian Patients with Diabetes: Prevalence, Etiology, and Risk Factors. Ther Clin Risk Manag. 
2017;13:1-7.

11. Boyko EJ, Fihn SD, Scholes D, Chen CL, Normand EH, Yarbro P. Diabetes and the Risk of Acute Urinary Tract Infection Among Postmenopausal Women. Diabetes Care. 2002;25(10):1778-83.

12. Nicolle LE. Urinary Tract Infections in the Older Adult. Clin Geriatr Med. 2016;32(3):523-38.

13. Laupland KB, Zygun DA, Davies HD, Church DL, Louie TJ, Doig CJ. Incidence and Risk Factors for Acquiring Nosocomial Urinary Tract Infection in the Critically ill. J Crit Care. 2002;17(1):50-7.

14. Vasudevan R. Urinary Tract Infection: An Overview of the Infection and the Associated Risk Factors. J Microbiol Exp. 2014;1(2):1-15.

15. Van Der Kooi TII, De Boer AS, Manniën J, Wille JC, Beaumont MT, Mooi BW, et al. Incidence and Risk Factors of Device Associated Infections and Associated Mortality at the Intensive Care in the Dutch Surveillance System. Intensive Care Med. 2007;33(2):271-8.

16. Yongzhi L, Shi Y, Jia L, Yili L, Xingwang Z, Xue G. Risk factors for Urinary Tract Infection in Patients with Urolithiasis - Primary Report of a Single Center Cohort. BMC Urol. 2018;18(1):1-6.
17. Butler SO, Btaiche IF, Alaniz C. Relationship Between Hyperglycemia and Infection in Critically Ill Patients Outline Normal Glucose Metabolism Glucose Metabolism in Critical Illness Hyperglycemia Definition Complications Pathogenesis of Hyperglycemia-Associated Infection Hyperglycemia an. Pharmacotherapy. 2005;25(7):963-76.

18. World Health Organization. Report on the Burden of Endemic Health Care-Associated Infection Worldwide Clean Care is Safer Care. World Heal Organ. 2011;1-40.

19. Saint S, Greene MT, Krein SL, Rogers MAM, Ratz D, Fowler KE, et al. A Program to Prevent Catheter-Associated Urinary Tract Infection in Acute Care. N Engl J Med. 2016 Jun 2;374(22):21119.

20. Chenoweth C, Saint S. Preventing Catheter-Associated Urinary Tract Infections in the Intensive Care Unit. Crit Care Clin. 2013;29(1):19-32.

21. Bichler K, Eipper E, Naber K, Braun V, Zimmermann R, Lahme S. Urinary infection stones. Int J Antimicrob Agents. 2002 Jun;19(6):488-98. 